\title{
10
}

\section{Sailing between worlds: The symbolism of death in northwest Borneo}

\author{
Katherine Szabó \\ Anthropology Program, University of Guam, Guam \\ kszabo@uguam.uog.edu \\ Philip J. Piper \\ Archaeological Studies Program, University of the Philippines, Diliman, Philippines \\ Graeme Barker \\ McDonald Institute for Archaeological Research, University of Cambridge, United Kingdom
}

\section{Introduction}

The Niah Caves complex in northwest Borneo is best known for its early Homo sapiens remains, but the various Niah entrances and nearby caves also contain a wealth of archaeological deposits from later time periods. The rich metal-age record (from c. 2000 years ago) of Niah is nearly exclusively represented by burials, and while some attention has been directed to understanding the West Mouth cemetery zone (e.g. B. Harrisson 1967; Zuraina 1982), other deposits have received less attention. Kain Hitam was one of the last sites in the Niah area to be excavated by Tom and Barbara Harrisson, and only received brief or popular treatment in the published literature (e.g. T. Harrisson 1958, 1960, 1964). Nevertheless, it has been regarded as a remarkable expression of metal-age mortuary ritual and the Kain Hitam rock art has been mentioned numerous times in press (e.g. Ballard et al. 2004; Lape et al. 2007). Based on a study of the field archive and curated materials, we present here details of the Kain Hitam mortuary site. We further assess claims about cultural affinities for the site (e.g. Chêng 1969) and situate Kain Hitam within the larger realm of commentary on Southeast Asian 'ship-of-the-dead' rites.

\section{Background}

Kain Hitam was discovered by Barbara Harrisson in 1958, when excavations in the various mouths of the Niah Caves were well underway (see Figure 1). On the cave floor, a group of dugout canoes lay 'beached' (Figure 2), and closer inspection revealed associated scatters of human bone, shell, earthenware and trade ware. A profusion of red pictographs was also noted, 


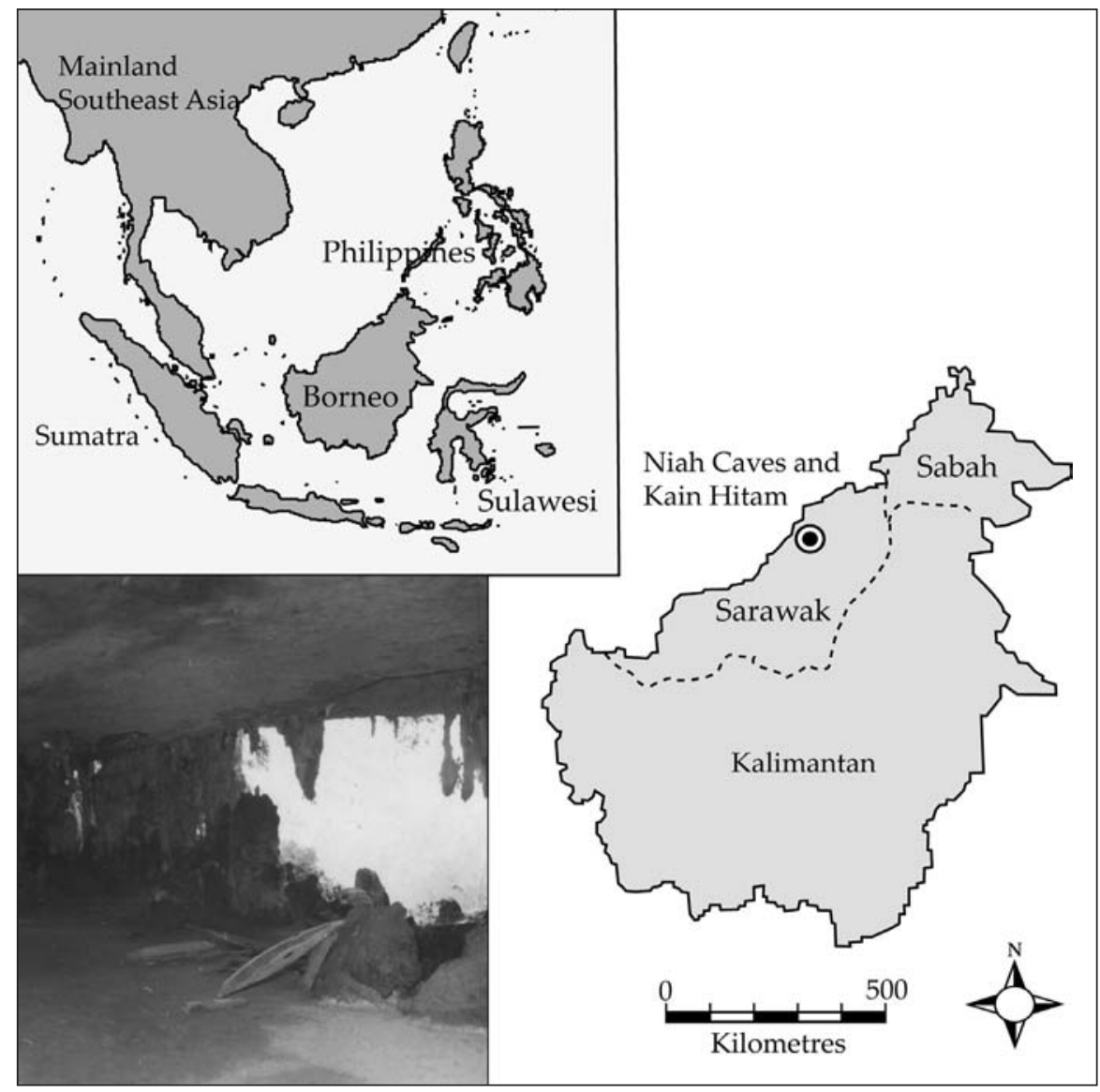

Figure 1. Map to show the location of Kain Hitam within Southeast Asia and Borneo. The picture on the lower left is of the Upper Cave at discovery, looking out from the rock art towards the entrance.

forming a $46 \mathrm{~m}$ panel along the west wall and acting as a back-drop 'mural' to the boats. The cave has opposing north and south openings on different levels, with a steep slope connecting the two. The rock-art mural is in the Upper Cave, which is the area largely considered in this paper. The Lower Cave had a smaller number of boat burials, and, as revealed by the photographic and artefact archive, was also excavated by Harrisson.

It appears from the photographic archive that much of the excavation was done by brush, with provenance of artefacts recorded by grid-square and depth. All material was accessioned on site. Deposits were shallow, with rarely more than $15 \mathrm{~cm}$ of deposit removed before reaching a layer of flowstone. Tom Harrisson published very little on Kain Hitam - or the 'Painted Cave' as it is otherwise known. ${ }^{1}$ All excavated material is held in the Sarawak Museum Kuching or Niah National Park branches, and includes unworked and worked shell, human bone, bone artefacts, bronze, earthenware and trade ware ceramics, and glass artefacts, while the paper archive contains some of Tom Harrisson's original field notes, on-site renderings of the spatial distribution of artefacts, and unpublished correspondence and manuscripts on aspects of the archaeological assemblage.

The material record

In April 2006, parts of the Kain Hitam assemblage were studied by Szabó and Piper, and the photographic and paper archives were digitised. Material physically analysed during this period included unworked and worked shell, and bone, bronze and glass artefacts. 


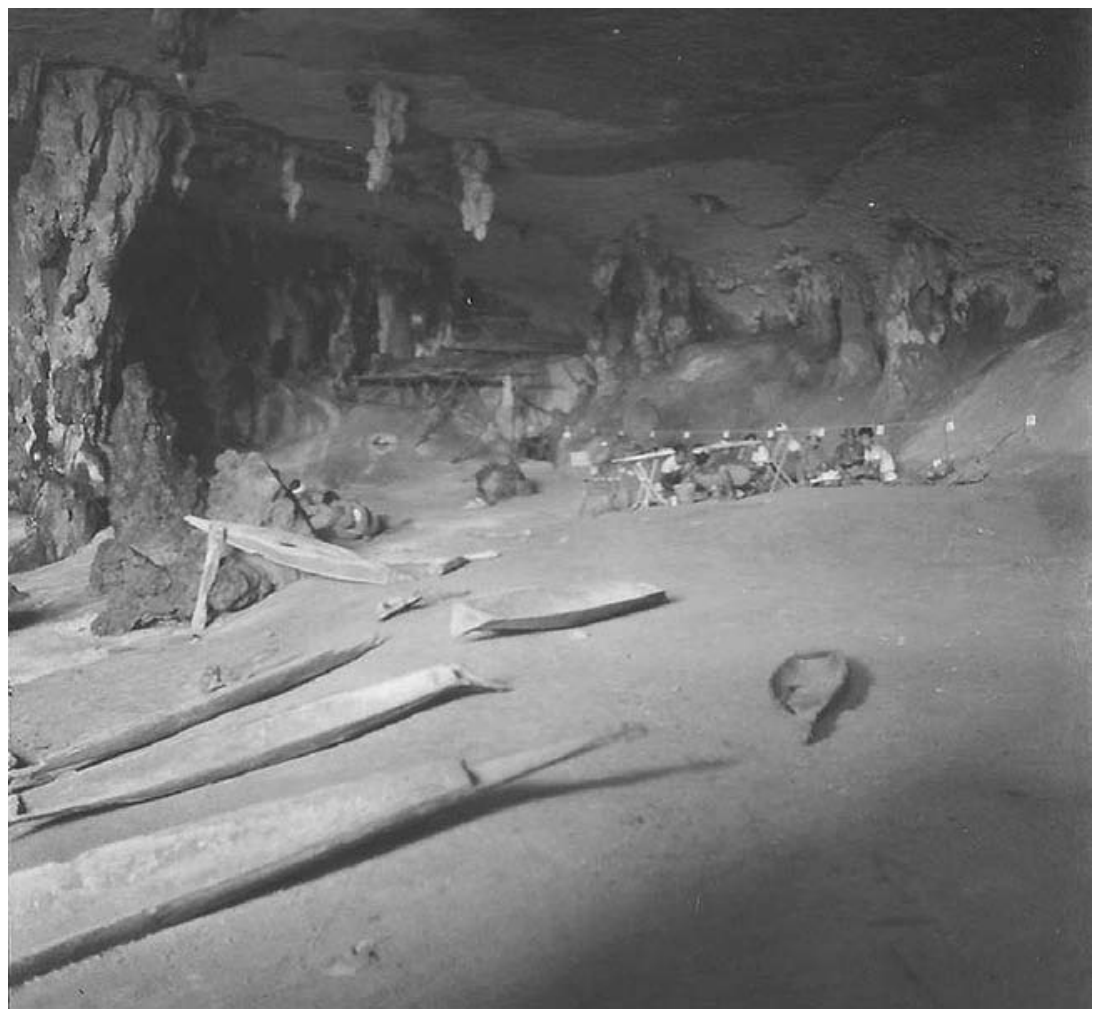

Figure 2. View of part of the Kain Hitam showing death ships in situ before the area is gridded for excavation.

\section{The 'death ships'}

A number of dugout wooden canoes were identified in the Upper Cave with an unknown smaller number located in the Lower Cave. Harrisson puts the Upper Cave number at 16, however each 'death ship' (following the terminology of T. Harrisson) consisted of two parts: an upper and lower 'boat' which slotted together, and it is unclear whether his numerical value related to whole coffins or individual halves. Most of the canoes were instantly associated by Harrisson with standard Dyak river perahu, although slightly smaller and shallower (T. Harrisson 1958:200). One of the death ships was significantly smaller in size, and labelled as a 'child coffin'. The spatial arrangement of the death ships was recorded on-site by Harrisson, before any movement of archaeological materials ${ }^{2}$ (see Figure 3). The boats were largely oriented along an east-west axis, and were 'pulled up' on a gently sloping surface, which was separated from the rock-art panel by a $7 \mathrm{~m}$ long flat expanse. This area between the death ships and the rock art is notably lacking in material culture, which is found in profusion around the death ships themselves and on a travertine platform adjacent to the rock-art panel. The discovery of a wooden post with a $\mathrm{v}$-shaped end still propping up the stern of death ship A1 indicates that at least some of the boats were literally 'facing' the rock art. Harrisson (1958:200) states that it was likely both ends of the boats were elevated using such posts, perhaps by analogy with his Sabah data (e.g. Harrisson and Harrisson 1971:48-49).

While the death ships resembled standard river craft, the bowsprits of the Kain Hitam death ships were elongate and carved with representations of various stylised animal heads. Easily recognisable are those of crocodiles, in particular (see Figure 4), however clouded leopards (Pardofelis nebulosa) and a 'sabre-toothed dragon' (Harrisson 1958:200, 203) were also present. It would appear from the Harrisson archive that human remains were not found inside the death 


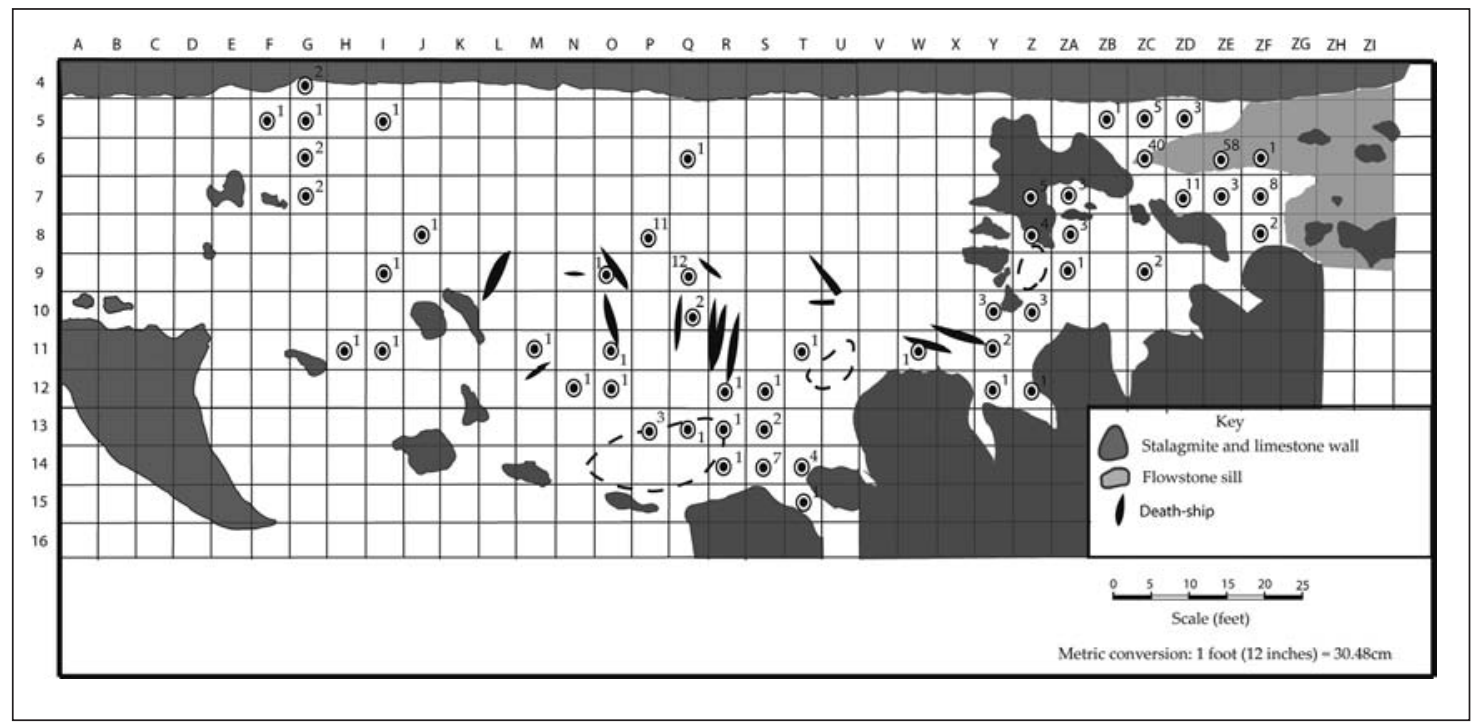

Figure 3. Schematic plan view of Kain Hitam, with the locations of all shell, bone, glass and metal artefacts in relation to the death ships. The numbers represent individual artefacts present. Areas in broken lines represent the extent of scattered pieces of a single death ship (redrawn from Tom Harrisson's site plans).

ships themselves, but rather were scattered around the boats. Their poor condition is at odds with the excellent state of preservation of most other material recovered from the Kain Hitam deposits and suggests the remains, once emptied from the coffins, received no further special treatment. While such an elaborate death staging would seem to conflict with such apparently casual treatment of the skeletal remains themselves, there are certainly precedents; generally based on beliefs in which the soul is seen to leave the body after decomposition, leaving simply 'matter' in the form of bodily remains (see Huntington and Metcalf 1979:Chapter III passim).

Other locales in Southeast Asia and the Pacific have furnished evidence of boat burials, where the body is interred within a boat or boat-like coffin (e.g. Spriggs et al. 2005:81 for Aru, Bellwood et al. 2007 for Vietnam, and Tenazas 1986 for the Philippines). While a comparative analysis of boat-associated mortuary practices is not the goal of this paper, it is worth pointing out that we do not believe the Kain Hitam death ships acted as coffins associated with single bodies, nor that the scattering of the human remains is a result of site disturbance. The remarkable preservation of the often-fragile death ships and the elevated position of death ship A1 (mentioned above) suggest that taphonomic agents such as medium-large carnivores and/or scavengers have not seriously interfered with the mortuary setting. Furthermore, the 1000-year span of the death ships themselves (see below), coupled with the many bags of fragmented human remains, suggest the same death ships were used repeatedly. A more parsimonious explanation is that the death ships were receptacles for bodies, to facilitate the transition to the afterlife. After the successful passage of the soul, the earthly remains were of little import, and simply 'cleared away'. For ethnographic parallels within Southeast Asia, see Huntington and Metcalf (1979:86-91).

\section{Bone artefacts}

In total, 75 complete or fragmentary bone artefacts were recorded from the Sarawak Museum archive (see Table 1). These include 24 finished and unfinished cylindrical beads, one barrel bead, one bead curated to make a toggle, 10 'ear cuffs' (Figure 5a), one rectangular plaque made from a male pig canine with holes bored in each corner, three teeth with holes bored through the root, two carved fragments of soft-shell turtle carapace/plastron (Figure 5c), two bead spacers (Figure 5b), one expedient bone point and one formal bone point. Where identifiable, different 
skeletal elements from various taxa had been utilised, including the radius, ulna, humerus, femur and metapodials of monkeys, squirrels, civet cats and small deer, the carapace or plastron of soft-shell turtles and bird bone (see Table 1). Further observations of techniques associated with bone-ornament production will be presented elsewhere. Holes drilled through the teeth of clouded leopard, civet cat and dog (cf. Canis familiaris), as well as those seen in the bead spacers, are absolutely straight, with no evidence of bevelling or counter-sinking. Such perforation morphology is generally indicative of the use of metal-tipped drills (Szabó 2005:264; Basilia et al. 2006). Also worthy of note are four shark vertebrae, one of which has a large, worn, central perforation and an abraded perimeter.

\section{Shell artefacts}

Artefacts produced for shell are less common than those in bone within the Kain Hitam assemblage, but nevertheless show a range of forms and raw materials. There are 24 shell artefacts, including a perforated Conus sp. spire, two disc beads hewn from Melo sp. shell (Figure 5d), two Cypraea annulus shells with the dorsum removed, one Nassarius pullus with the dorsum removed and ground, and two Oliva sp. shells with worn holes at the apex. A collection of three Anadara granosa and 11 Polymesoda erosa valves has hewn holes at the umbo, and technological analysis supports an interpretation of them as shell sinkers from casting nets (Szabó and Yang In preparation). The final 'artefact' is an unmodified Vexillum cf. citrinus which, as an occupant of clean coral sand, is clearly an import from some distance away.

\section{Earthenware and ceramic trade wares}

The trade-ware ceramics from Kain Hitam were not viewed by the authors, but the paper archive revealed that a number of sherds were sent to the Ashmolean Museum, Oxford, in 1963 for comment. According to correspondence between Ms Eine Moore (Sarawak Museum) and Ashmolean staff, the Kain Hitam ceramic trade wares can generally be characterised as 'Yueh-ware' (following Gompertz 1958) and ascribed to the T'ang Dynasty (618-906 AD), with a handful of examples possibly more closely associated with early Northern Sung wares (from 960 AD). ${ }^{3}$ The assemblage consists mainly of smaller vessels, including jars, vases, bowls and ewers. Some bear lotus-leaf-pattern decoration. While seemingly early in a regional context (e.g. see Bellwood 1997:275), a number of sites in Sarawak contain volumes of trade wares contemporaneous with those at Kain Hitam - such as Bukit Saripah and various of the Santubong Delta sites (Harrisson 1958:200; Moore nd).

There is little information in Harrisson's notes about the earthenware pottery, but a number of details can be discerned from his on-site plans and keys. Firstly, earthenware pottery appears to be at least as abundant as ceramic trade wares within the site. The range of vessel forms includes double-spouted vessels, impressed and incised earthenware,

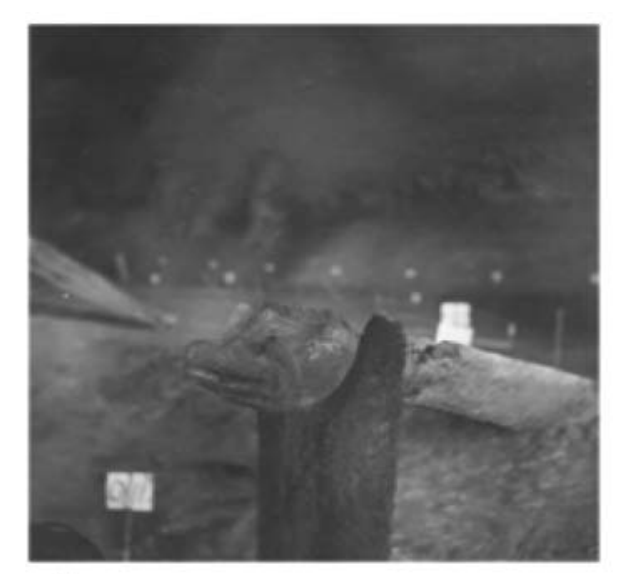

a

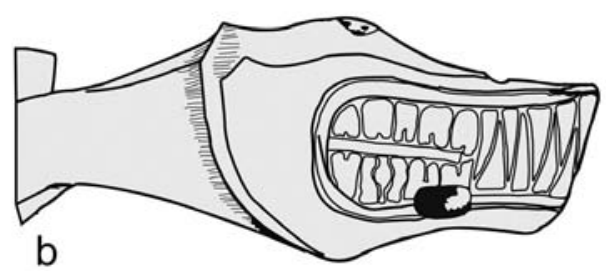

b

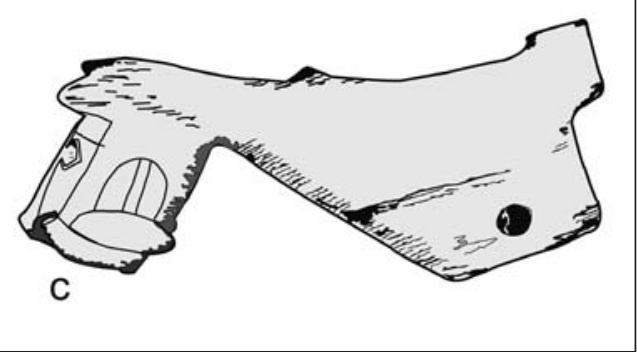

Figure 4. Details of bowsprits of death ships: (a) site photograph of death ship A13 with a crocodile bowsprit; (b) 'sabre-toothed dragon' bowsprit after Harrisson (1958:figure 5); (c) clouded leopard bowsprit after Harrisson (1958:Figure 4). 
Table 1. Bone artefacts recovered from Kain Hitam recorded by Szabó and Piper in 2006.

\begin{tabular}{|c|c|c|c|c|}
\hline Grid & Material & Common Name & Element & Artefact Type \\
\hline $1 / 9$ & cf. Amyda cartiliagena & Asian soft-shell turtle & Carapace/plastron. & Carved sub-cutineous bone \\
\hline$R / 13$ & Aves sp. & Bird & Tibiotarsus & Expedient point \\
\hline$R / 13$ & Aves sp. & Bird & Humerus & Finished bead \\
\hline $\mathrm{R} / 14$ & Indeterminate & Indeterminate & Unknown & Finished'ear cuff' fragment \\
\hline $\mathrm{R} / 19$ & Aves sp. & Bird & Longbone shaft fragment & Finished artefact fragment \\
\hline S/14 & Indeterminate & Indeterminate & Unknown & Finished'ear cuff' fragment \\
\hline$S / 14$ & Aves sp. & Bird & Humerus & Finished bead fragment \\
\hline$S / 14$ & Aves sp. & Bird & Longbone shaft fragment & Finished artefact fragment \\
\hline$S / 14$ & Aves sp. & Bird & Longbone shaft fragment & Finished artefact fragment \\
\hline$S / 14$ & Aves sp. & Bird & Longbone shaft fragment & Finished artefact fragment \\
\hline$S / 14$ & Aves sp. & Bird & Longbone shafl fragment & Finished artefact fragment \\
\hline$S / 14$ & Aves sp. & Bird & Longbone shaft fragment & Finished artefact fragment \\
\hline$S / 14$ & Indeterminate & Indeterminate & Caudal vertebra & Vertebra with bored hole \\
\hline $\mathrm{T} / 14$ & Indeterminate & Indeterminate & Longbone shaft fragment & Finished artefact fragment \\
\hline $\mathrm{T} / 14$ & Aves sp. & Bird & Longbone shaft fragment & Finished artefact fragment \\
\hline $\mathrm{T} / 14$ & Aves sp. & Bird & Longbone shaft fragment & Finished artefact fragment \\
\hline $\mathrm{Y} / 10$ & Indeterminate & Indeterminate & Unknown & Curated bead - toggle? \\
\hline $\mathrm{Y} / 11$ & Cercopithecidae & Leaf monkey/Macaque & Femur & Unfinished bead fragment \\
\hline Z/7 & Indeterminate & Indeterminate & Unknown & Fragment of bead separator \\
\hline Z/7 & Cercopithecidae & Leaf monkey/Macaque & Radius & Finished bead \\
\hline Z/7 & Petauristinae sp. & Flying squirrel & Femur & Unfinished artefact fragment \\
\hline Z/7 & Cercopithecidae & Leaf monkey/Macaque & Ulna & Unfinished bead \\
\hline Z/8 & Indeterminate & Indeterminate & Radius? & Finished bead fragment \\
\hline$Z / 8$ & Aves sp. & Bird & Tibiotarsus & Finished head fragment \\
\hline Z/8 & Sus sp. & Pig & Male lower canine & Artefact fragment \\
\hline$Z / 10$ & Aves sp. & Bird & Longbone shaft fragment & Finished bead fragment \\
\hline$Z / 10$ & Aves sp. & Bird & Longbone shaft fragment & Finished artefact fragment \\
\hline$Z / 10$ & Sus sp. & Pig & Male lower canine & Artefact fragment \\
\hline Z/A7 & Aves sp. & Bird & Longbone shaft fragment & Finished bead \\
\hline Z/A7 & Indeterminate & Indeterminate & Longbone shaft fragment & Finished bead fragment \\
\hline Z/A7 & Cercopithecidae & Leaf monkey/Macaque & Radius & Finished bead fragment \\
\hline Z/B7 & Indeterminate & Indeterminate & Fibula? & Shaft of a point \\
\hline Z/C5 & Viverridae & Civet Cat & Tibia & Finished bead fragment \\
\hline $2 / C 5$ & Cercopithecidae & Leaf monkey/Macaque & Radius & Finished bead \\
\hline Z/C5 & Indeterminate & Indeterminate & Unknown & Unfinished artefact fragment \\
\hline Z/C5 & cf. Sciuridae & Squirrel? & Femur & Unfinished artefact fragment \\
\hline Z/C5 & Cercopithecidae & Leaf monkey/Macaque & Femur & Finished bead fragment \\
\hline
\end{tabular}




\begin{tabular}{|c|c|c|c|c|}
\hline Grid & Material & Common Name & Element & Artefact Type \\
\hline Z/C5 & Sus sp. & Pig & Male lower canine & Small plaque \\
\hline Z/C5 & Indeterminate & Indeterminate & Unknown & Piece of carved bone \\
\hline Z/C5 & cf. Amyda cartiliagena & Asian soft-shell turtle & Rib fragment & Point \\
\hline Z/C6 & Elasmobranch sp. & Shark/ray & Vertebra & Modified neural canal \\
\hline Z/C6 & Aves sp. & Bird & Longbone shaft fragment & Finished bead fragment \\
\hline Z/D5 & Indeterminate & Indeterminate & Longbone shaft fragment & Finished artefact fragment \\
\hline Z/D7 & cf. Tragalus sp. & Mouse deer & Femur & Complete 'ear cuff' \\
\hline Z/D7 & Indeterminate & Indeterminate & Longbone shaft fragment & Finished artefact fragment \\
\hline Z/D7 & Indeterminate & Indeterminate & Longbone shaft fragment & Finished 'ear cuff' fragment \\
\hline Z/D7 & Indeterminate & Indeterminate & Femur & Finished 'ear cuff' fragment \\
\hline Z/D7 & Cercopithecidae & Leaf monkey/Macaque & Ulna & Finished bead fragment \\
\hline Z/D7 & Petauristinae sp. & Flying squirrel & Humerus & Finished bead \\
\hline Z/D7 & Indeterminate & Indeterminate & Longbone shaft fragment & Finished 'ear cuff' fragment \\
\hline Z/D7 & Indeterminate & Indeterminate & Longbone shaft fragment & Finished artefact fragment \\
\hline Z/D7 & Indeterminate & Indeterminate & Longbone shaft fragment & Finished artefact fragment \\
\hline Z/D7 & Indeterminate & Indeterminate & Longbone shaft fragment & Barrel'bead'fragment \\
\hline Z/D7 & Cercopithecidae & Leaf monkey/Macaque & Humerus & Complete 'ear cuff' \\
\hline Z/E6 & Cercopithecidae & Leaf monkey/Macaque & Radius & Finished bead \\
\hline Z/E6 & Cercopithecidae/Hylobates & Leaf monkey/Macaque/Gibbon & Metatarsal & Finished bead \\
\hline Z/E6 & Phasianidae & $\begin{array}{l}\text { Pheasant/wild fowl/ domestic } \\
\text { chicken }\end{array}$ & Tibiotarsus & Unfinished artefact fragment \\
\hline Z/E6 & Indeterminate & Indeterminate & Longbone shaft fragment & Complete 'ear cuff' \\
\hline Z/E6 & Aves sp. & Bird - fowl-sized & Tibiotarsus & Finished bead \\
\hline Z/E6 & Cercopithecidae & Leaf monkey/macaque & Ulna & Finished bead \\
\hline Z/E6 & Viverridae & Civet Cat & Canine & Bored hole pendant \\
\hline Z/E6 & Pardofelis nebuiosa & Clouded leopard & Canine & Bored pendant \\
\hline Z/E6 & Indeterminate & Indeterminate & Unknown & Fragment of bead separator \\
\hline Z/E7 & Indeterminate & Indeterminate & Longbone shaft fragment & Unfinished artefact fragment \\
\hline Z/E7 & Cercopithecidae & Leaf monkey/macaque & Femur & Finished 'ear cuff' fragment \\
\hline Z/E7 & Muntiacus sp. & Muntjac & Metatarsal & Finished artefact fragment \\
\hline Z/F6 & Cercopithecidae & Leaf monkey/macaque & Femur & Complete 'ear cuff' \\
\hline Z/F7 & Cercopithecidae & Leaf monkey/macaque & Femur & Unfinished artefact fragment \\
\hline Z/F7 & cf. Petauristinae sp. & Flying squirrel? & Radius & Finished bead (in two fragments) \\
\hline Z/F7 & Indeterminate & Indeterminate & Unknown & Finished bead \\
\hline Z/F7 & Indeterminate & Indeterminate & Unknown & Finished bead \\
\hline Z/F7 & Aves sp. & Bird & Longbone shaft fragment & Unfinished bead fragment \\
\hline Z/F7 & Canis familiaris & Dog & Canine & Bored pendant \\
\hline Z/F8 & Indeterminate & Indeterminate & Unknown & Finished artefact fragment \\
\hline
\end{tabular}




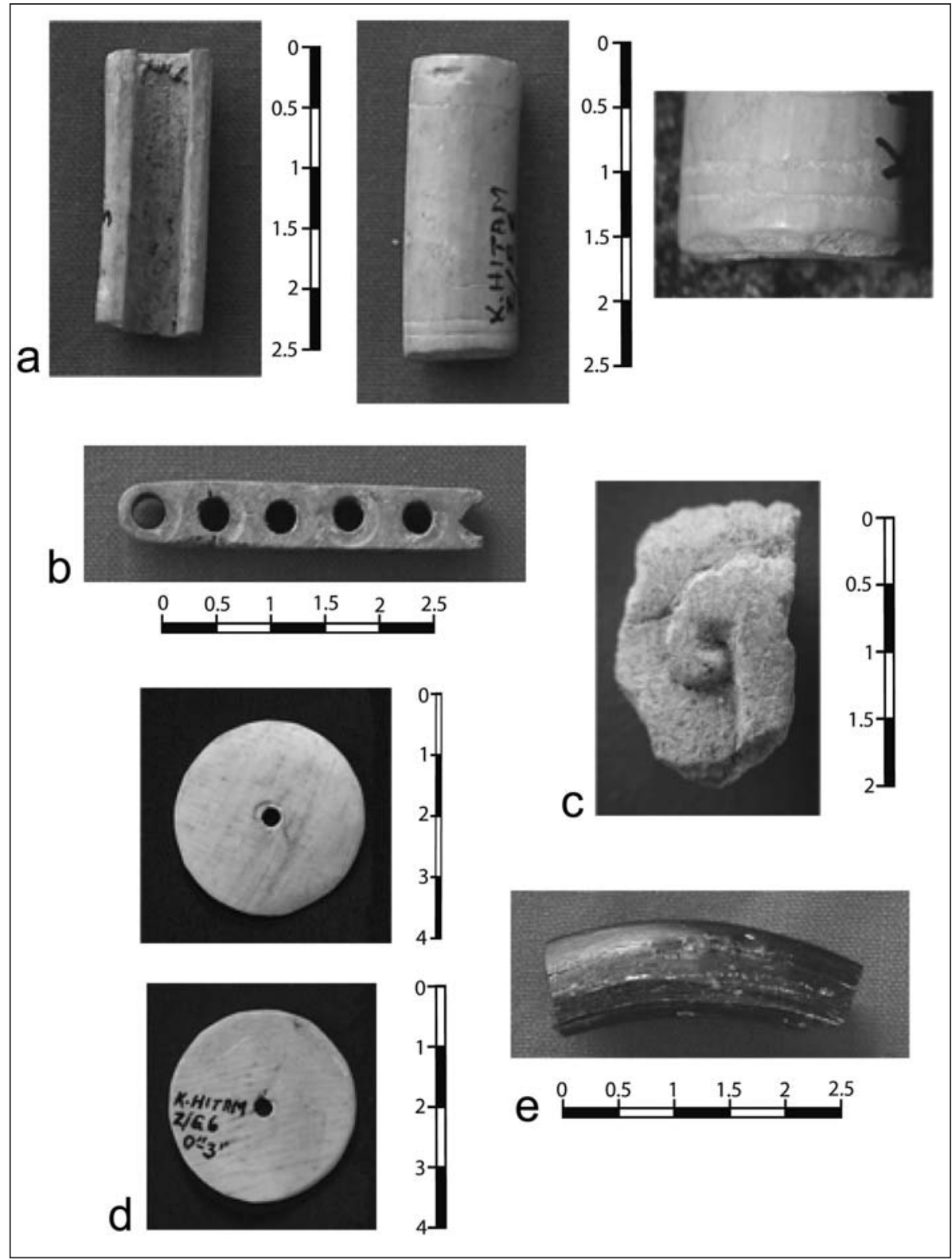

Figure 5. Artefacts from Kain Hitam: (a) three views of a bone cuff (Z/E6:0-3"). The cutting of the ends in stages following by grinding can be clearly seen, as well as the typical concentric incisions seen on most bone beads and cuffs. The image in the top right corner is at 10x magnification; (b) bone bead spacer $(\mathrm{Z} / 7: 0-3 ")$, with the impressions of beads visible; (c) soft-shell turtle carapace or plastron carved in low relief (I/9:0"). Two further pieces from Lobang Tulang suggest the motif may be that of a tree of life; (d) inner and outer views of a Melo sp. disc bead (Z/E6:0-3"); (e) fragment of reworked blue glass bracelet (N/12:0"). Scale bars are in centimetres.

'corrugated' (paddle-impressed?) earthenware, box vessels with lids, and a further category called 'nose pots' by T. Harrisson. The distribution of earthenware vessels in Kain Hitam also matches the spatial patterning observed in the trade wares and other artefacts (see below for further discussion of spatial patterning).

\section{Beads and ornaments in glass and semi-precious stone}

A total of 185 beads and one fragment of a glass bracelet were recovered from the Kain Hitam upper and lower caves, and a number of 'grottos' within Kain Hitam investigated by the Har- 
rissons. The majority ( 82 percent) are glass 'Indo-Pacific' beads (terminology following Francis 2002), in an assortment of colours, including red, yellow, orange, green, black, white and blue. None of the beads was chemically analysed in this recent study, but details of technology were recorded, including whether beads were generated through 'drawing' or 'coiling' techniques. The coiling of molten glass around the central mandrel to produce beads is distinctive of Chinese glass-making technologies, whereas pulling molten glass lengthwise along the mandrel has its roots in Indian technologies (Francis 2002:Chapter 8; Munan 2005:27). Out of 153 IndoPacific beads, 100 were drawn and 68 were coiled, clearly indicating that the Kain Hitam bead assemblage is composed of trade items of mixed origin. ${ }^{4}$ This is reinforced by chemical analysis of a sample of glass beads from Kain Hitam and other Sarawak locales sent by T. Harrisson to the Corning Glass Museum in New York. The variation in lead values within the Sarawak samples indicates that while some beads correspond to 'high-lead' Chinese glass, others do not (Brill 1999:171, XV E).

The single bracelet fragment is of dark blue translucent glass, with an internal diameter of c. $7 \mathrm{~cm}$ and a triangular cross-section (see Figure 5e). Closer inspection under a low-power microscope indicated that the surface of the bracelet had been extensively ground, with the two corners intersecting with the interior of the bracelet having been ground flat on single facets. This is not the first time that the grinding of glass bracelets has been noted for Borneo, with a transparent green glass bracelet fragment sent to the Corning Glass Museum being published as having 'some ground surfaces' (Brill 1999:171). Interestingly, the morphology after grinding matches precisely the cross-section common in metal-age bracelets produced in Tridacna sp. shell, with one such example being recovered from the upper/metal age deposits of the Gan Kira entrance of the Niah Caves. A further eight beads in varying morphologies were produced from semi-precious stone, including carnelian, crystal, onyx and unidentified dark grey stone. A barrel bead produced in baked clay is clearly an imitation of the opaque red glass barrel beads also present in the Kain Hitam assemblage.

\section{Bronze and precious metal artefacts}

There are only three bronze artefacts within the Kain Hitam assemblage and none in iron. Two of the bronze pieces are identical Chinese coins, and a note in T. Harrisson's hand links it to the reign of Emperor Kao Tsu (618-625 AD) in the Early T'ang dynastic period. The third bronze artefact is a fragment of a small vessel with a rim diameter of c. $7 \mathrm{~cm}$. The only other evidence of metal at Kain Hitam is a human incisor with three gold plugs. The insertion of gold plugs into human incisors is also seen in proto-historic-period sites in the Philippines, such as Calatagan (see Barretto 2002), and in the Bolinao skull, as well as the First Millennium AD deposits in Burma (Hudson 2003), however these plugs have a 'fish-scale' appearance not seen in the Kain Hitam tooth.

\section{Unworked shell}

Eleven large boxes of unworked fresh-water shell from Kain Hitam are present at the Niah National Park branch of the Sarawak Museum. Hundreds of individuals of the stagnant/slowmoving water species Cipangopaludina sp. and Pila ampullacea occur, along with valves of the brackish water bivalve Polymesoda erosa and lesser numbers of Melanoides tuberculata and Ellobium aurismidae. These species have been recovered throughout the Niah Caves archaeological sites, associated with later deposits, in most cases clearly representing shell midden (Szabó In preparation).

The occurrence of discrete fresh-water shell deposits within the Niah burial cave Lobang Tulang led Barbara Harrisson to comment that these, together with lumps of iron slag, 
represented the only evidence of 'casual incidents not linked to the burial rites' (B. Harrisson 1959-60:171). While this is certainly a viable interpretation, we feel the fresh-water shell may well be linked to burial rights. This interpretation is reinforced by the spatial distributions of the fresh-water shell remains, which map on to the highly patterned distributions of other artefact types. Fox (1970:72) has also noted the association between shellfish, sometimes covered in red pigment, and burials in the Tabon Caves sites of Palawan, just north of Borneo in the southwestern Philippines.

Rock art

The rock art was systematically photographed and sketched by a local artist, Paul Kerek, during excavations. While we have been able to scan the photograph proof sheets, we could not locate the sketches and paintings done by Kerek. The rock-art panel is so extensive, and the photographic archive so fragmented, that we will not endeavour to reproduce the panel in its entirety, nor statistically analyse motif occurrences here. Rather, we will discuss prominent motifs and the main themes. While the site has been visited on multiple occasions by the authors, present-day observations do little to supplement information from the Harrisson archive, as since 2006, much (if not most) of the rock art has been obscured by the growth of green micro-algae over the rock surface. All of the rock art has been executed in red pigment, and it has recently been demonstrated that this is not a hematite-based compound, but rather derives from an organic source, probably a tree resin (Pyatt et al. 2005). There is minimal evidence of superimposition of pictographs, and all of the mural components fall comfortably within the 'curvilinear red tradition' identified by Wilson for the western Pacific and the eastern reaches of Southeast Asia (2003). Thus, there is an overall cohesiveness to the rock art that, while not suggesting synchronicity, implies a totality in design and motivation. Dominant motifs include boats, isolated human figures and animals, interspersed with abstract curvilinear designs. The boats are the most strikingly dominant (Figures 6 and 7), with more than 20 examples still visible.

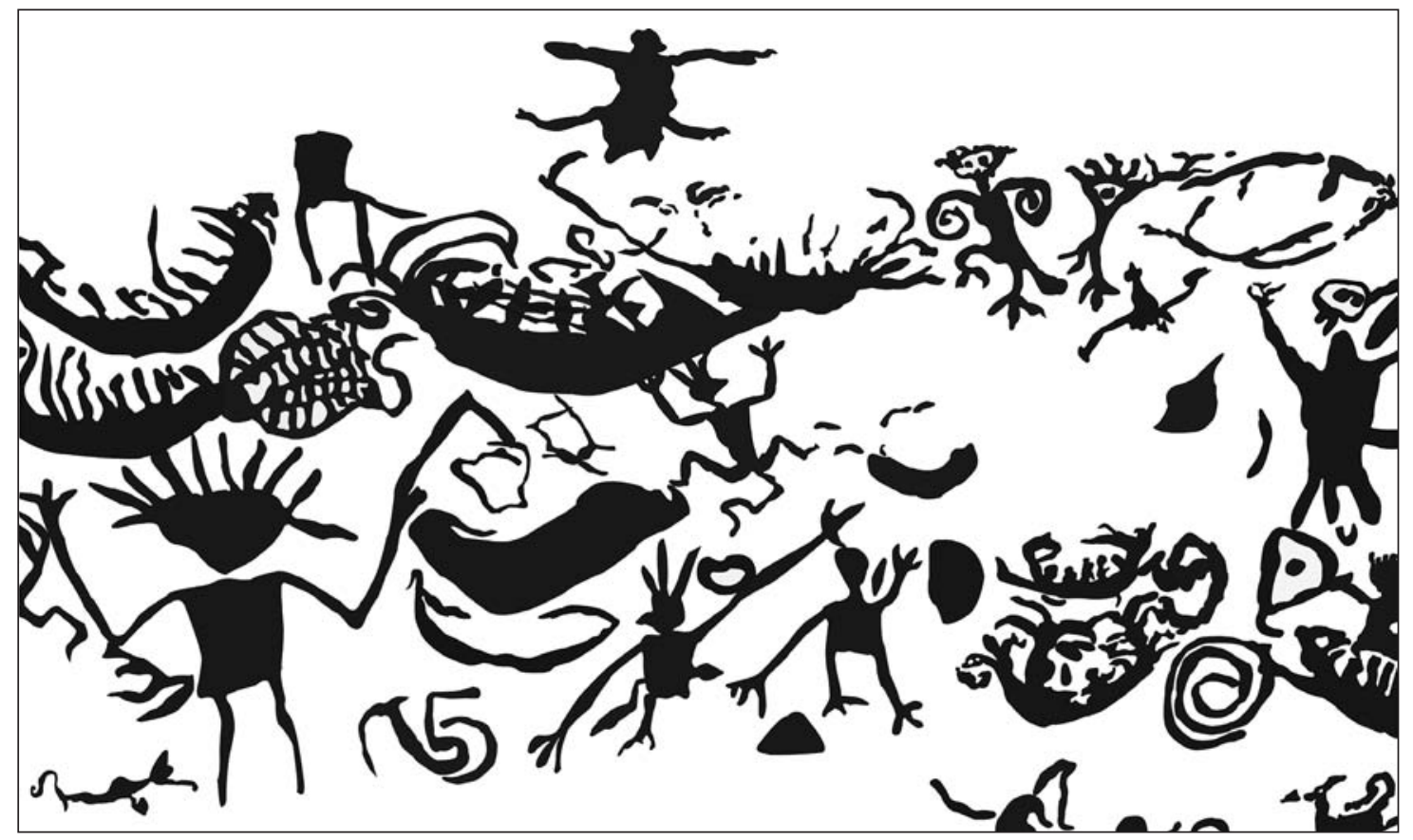

Figure 6. Section of the rock-art panel from Kain Hitam, including ships of the dead, anthropomorphs and animals. Note the trees of life emerging from some of the vessels and the double-crescentic motifs at the prow (drawn from a colour photograph taken in 2005 by Szabó and Piper). 
While the Kain Hitam boat representations have been compared with those from Timor (e.g. Glover 1972:42; Lape et al. 2007:4), it is unclear whether the two are in any way related. While it is argued that the Timorese boats contain visual traces indicating past maritime technologies, the Kain Hitam boat representations are stylised to such an extent that they contain no such information, but rather a wealth of symbolic imagery. At least eight boats have 'trees of life' sprouting from the deck and a recurrent double-crescent motif associated with the bows and/ or sterns (see also Adams 1977:97). Most of the boats contain rows of highly stylised figures, some with additional anthropomorphs in a row with hands joined (refer to Figure 6). Individual anthropomorphs outside boats are typically in active poses, though we hesitate to ascribe such postures to dancing (e.g. T. Harrisson 1958:202).

Recognisable animals include a crocodile (Figure 7), snails, turtles, quadruped mammals, and figures with both bird and human features. It could be argued that a number of the humanlike figures wear head dresses or costumes, however the common representation of a tail on such figures shrouds in ambiguity their human, or true, nature. As originally pointed out by T. Harrisson (1958), and elaborated on below, recognisable features of the Kain Hitam rock art clearly link with death symbolism, and thus the archaeological site at the panel's base.

\section{Notes on chronology and spatial patterning}

T. Harrisson obtained a number of radiocarbon dates on wood from the death ships in the 1960s. He was fully cognisant of the 'old-wood' problem regarding long-lived trees, and thus he employed a local Penan worker to construct a boat out of Belian (Eusideroxylon zwageri) wood and dated samples of this, along with the archaeological specimens, to check inbuilt age. The modern death ship returned a date of $276 \pm 80 \mathrm{BP}$, indicating a general inbuilt age of c. 250-300 years. The radiocarbon dates (Table 2 and Figure 8) indicate a c. 1000-year spread for the death ships, beginning around the early metal age - or even late Neolithic - (c. 2300 BP) and continuing until around the 10th century $\mathrm{AD}$. The latter part of this age range coincides well with the chronological reckonings based on ceramic trade-ware types and Chinese coins, but also affirms a significant pre-trade-ware period for the Kain Hitam site. It should be mentioned that two radiocarbon dates on charcoal from the Harrisson archive were recently obtained, both returning Pleistocene dates (see Table 2). These samples seem to derive from deposits surrounding broken flowstone underlying the visible deposits. Thus, while not shedding light on the material discussed here, these dates demonstrate an older history for Kain Hitam.

While it is clear from the radiocarbon dates that the Kain Hitam sites span the introduction of mainland Asian ceramic trade wares to the region, it is of particular significance that the highfired ceramic, glass and bronze distributions map precisely on to intra-site spatial patterning observed in the local earthenwares, bone and shell artefacts (see Figures 3, 9 and 10). Indeed, apart from the gross distributions around the death ships and

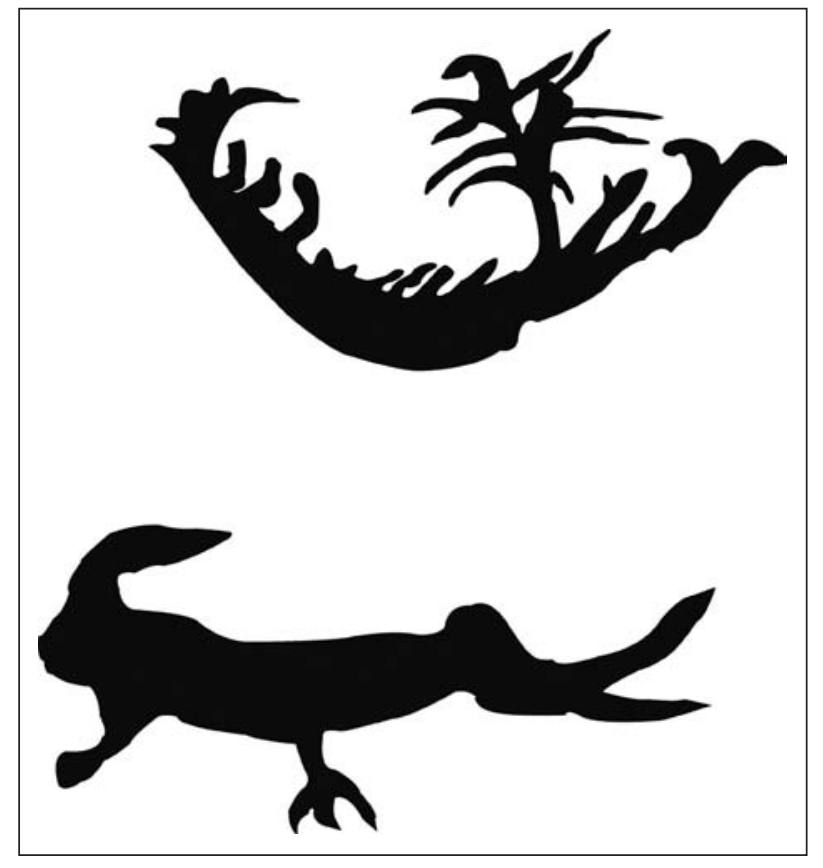

Figure 7. Two further pictographs from the Kain Hitam rock-art panel, showing a ship of the dead with emergent tree of life, and a crocodile (drawn from a black and white photograph from the Harrisson archive). 
Table 2. Radiocarbon determinations for Kain Hitam and the Samti death-ship site. All dates are Harrisson's, except for the two charcoal dates obtained by Szabó, Piper and Barker in 2006 on material collected by T. Harrisson.

\begin{tabular}{|c|c|c|c|}
\hline Sample code & Sample & Radiocarbon age (BP) & Calibrated dates (1 sigma) \\
\hline GX0212 & Death Ship X - Upper Cave & $1780 \pm 150$ & (77 AD:413 AD) - 1 \\
\hline \multirow[t]{3}{*}{ GX0213 } & Fragment of dense wood & $2115 \pm 125$ & $(356 \mathrm{BC}: 286 \mathrm{BC})-0.215675$ \\
\hline & & & $(252 B C: 251 B C)-0.00257$ \\
\hline & & & $(234$ BC:1 AD) - 0.781756 \\
\hline \multirow[t]{2}{*}{ GX0214 } & Wood lower cave (Death Ship A20?) & $1450 \pm 125$ & (433 AD:498 AD) - 0.217013 \\
\hline & & & (501 AD:675 AD) -0.782987 \\
\hline \multirow[t]{4}{*}{ GX0307 } & Child Death Ship A4 & $2300 \pm 80$ & $(485 B C: 464 B C)-0.056146$ \\
\hline & & & $(448$ BC:444 BC) - 0.009874 \\
\hline & & & $(416 \mathrm{BC}: 342 \mathrm{BC})-0.404504$ \\
\hline & & & $(326 B C: 204 B C)-0.529476$ \\
\hline \multirow[t]{3}{*}{ GX0308 } & Modern Death Ship & $276 \pm 80$ & (1486 AD:1669 AD) - 0.898092 \\
\hline & & & (1780 AD:1798AD) - 0.080257 \\
\hline & & & (1944 AD:1950 AD) - 0.021651 \\
\hline \multirow[t]{2}{*}{ GX0309 } & Death Ship Al 8 - Lower Cave & $1045 \pm 80$ & (891 AD:1042 AD) - 0.958061 \\
\hline & & & (1107 AD:1117 AD) -0.041939 \\
\hline \multirow[t]{2}{*}{ GX0310 } & Mixed bone sample - Upper Cave & $4135 \pm 330$ & $(3264 B C: 3242 B C)-0.017356$ \\
\hline & & & $(3103$ BC:2205 BC) - 0.982644 \\
\hline 0xA 16694 & Charcoal from grid square Z/C5: 6-9 & $16515 \pm 60$ & Uncalibrated \\
\hline 0xA16695 & Charcoal from grid square $R / 13: 3-6$ & $26510 \pm 120$ & Uncalibrated \\
\hline
\end{tabular}

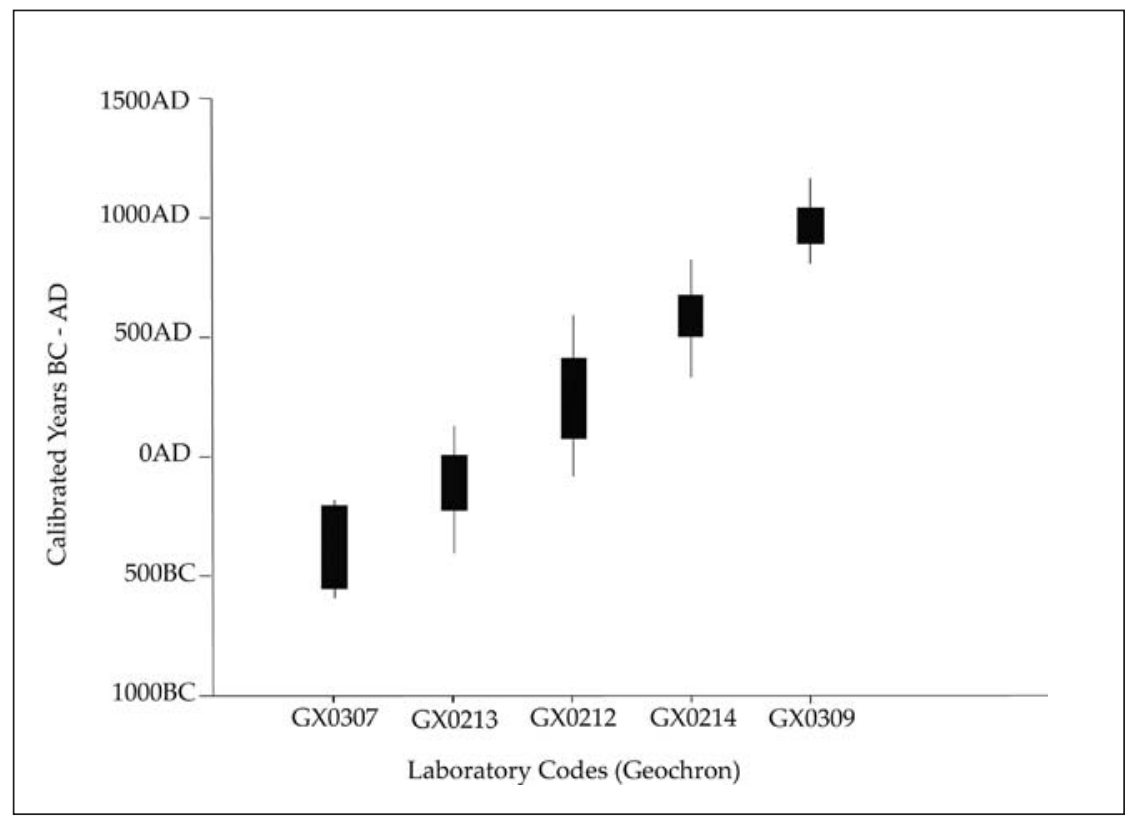

Figure 8. Box and whisker plot showing the calibrated radiocarbon dates for Kain Hitam at 1 and 2 sigma. Sample GX0213 is from the Samti death-ship site in the Niah Cave system. Full details of radiocarbon dates are presented in Table 2 . Harrisson's modern death ship and the aggregate bone date have been excluded from this graph. 


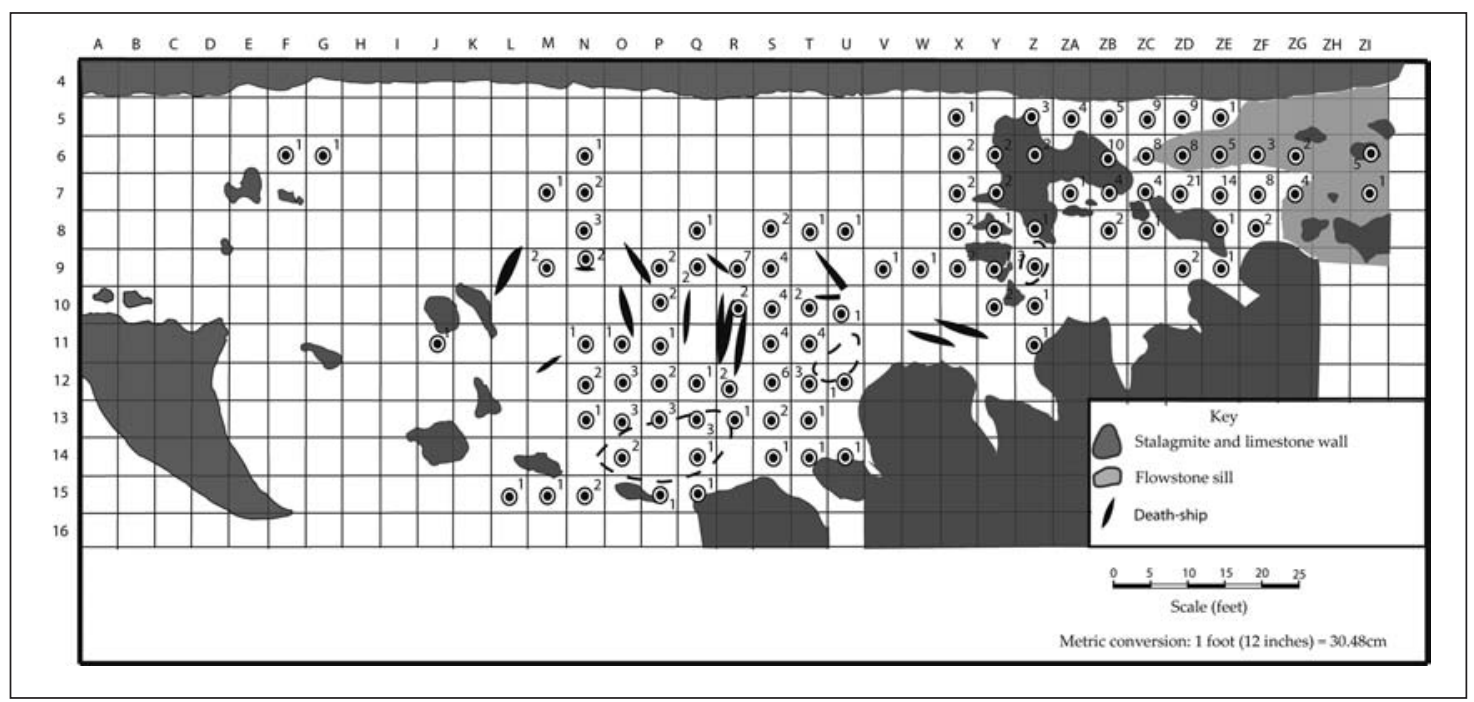

Figure 9. Distribution plan of occurrence of double-spouted vessel sherds at Kain Hitam. Numbers represent vessel fragments. Areas within dotted lines represent the scattered remains of individual death ships (redrawn from Tom Harrisson's original plans).

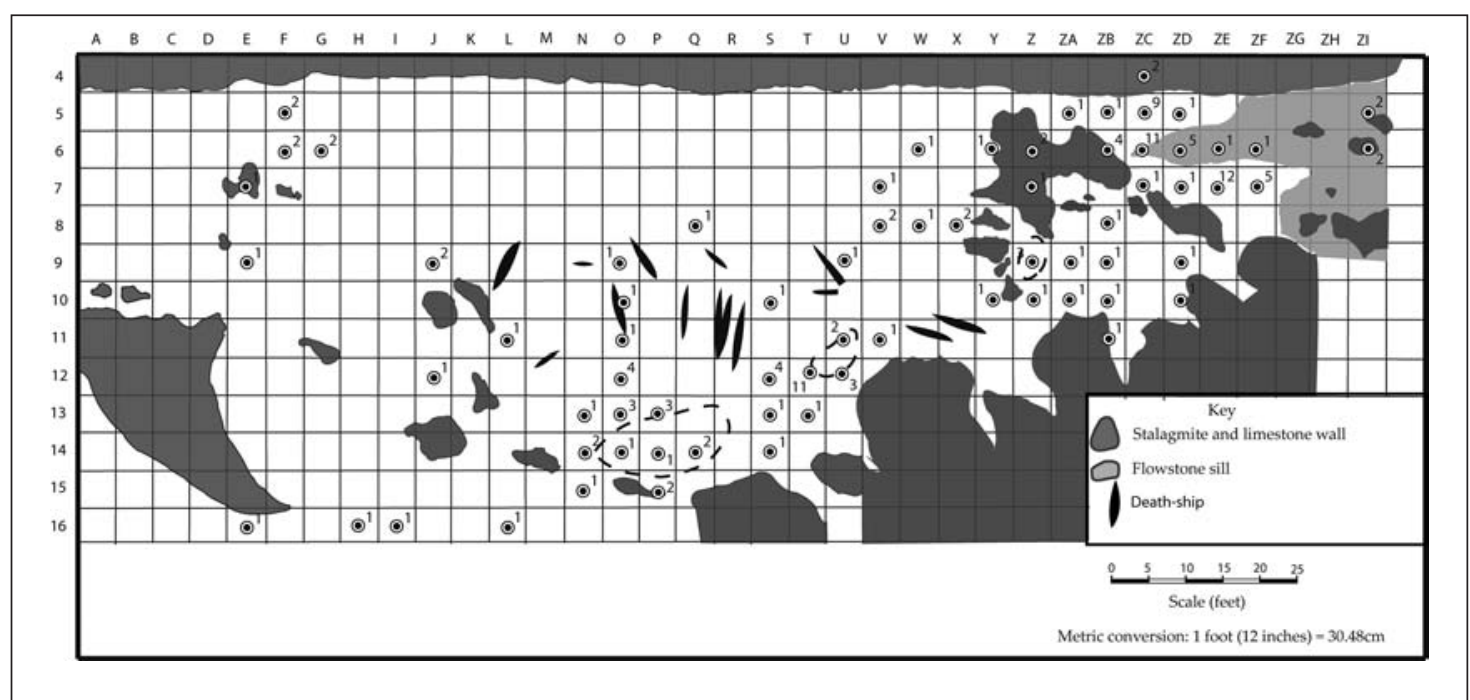

Figure 10. Distribution plan of occurrence of ceramic trade wares at Kain Hitam. Values represent individual vessels. Areas within dotted lines represent the scattered remains of individual death-ships (redrawn from Tom Harrisson's original plans).

travertine shelf, no differential patterning of different types of artefacts can be discerned. This observation contradicts any argument that the importation of these goods revolutionised local cultures in either a structural or symbolic sense. Furthermore, it also argues strongly against the influx of new peoples synchronous with the extension of trade routes, replacing and/or transforming local cultures (e.g. Chêng 1969). It is also worthy of note that although artefacts in bone and shell are often, implicitly or explicitly, associated with Neolithic deposits in Southeast Asia (e.g. Francis 2002:151), the radiocarbon chronology points to a metal-age association at Kain Hitam.

\section{Archaeological representations of death: An Island Southeast Asian context for Kain Hitam}

While the use of death ships has parallels with only two other known sites in Sarawak (see below), the diverse types of material culture represented at Kain Hitam link it strongly to various locales within the Niah Caves complex. Pieces of bone carved with relief-scroll designs identical to the distinctive fragment recovered from Kain Hitam (Figure 5c), have also been excavated 
from the Lobang Tulang mouth of the Niah Caves (T. Harrisson and Medway 1962:Plate 2), where tubular bone beads were also recovered in some numbers (B. Harrisson 1958). Bone cuffs were recovered from the upper levels of Gan Kira, and bone bead separators were recovered from both Lobang Tulang and Gan Kira (Harrisson and Medway:Table 7). Lobang Tulang is a metal-age jar-burial site, while Gan Kira has two stratigraphic layers, of which the lower is Neolithic and the upper strata, with primary extended burials, is associated with the metal age (Piper and Szabó Unpublished data). The inter-site linkages observable in the bone artefacts can also be seen in artefacts produced from shell. We know of no analogues for the hewn disc beads in Melo sp. in Island Southeast Asia, but those recovered from Kain Hitam have exact parallels in examples from Gan Kira. A less restrictive spatio-temporal distribution is seen in the ground and perforated Conus sp. spires which occur widely across the Neolithic and metal ages of the Philippines and other locales in Borneo (Szabó 2005; Szabó Unpublished data). The same can be said of beads in Cypraea annulus, Oliva spp., Pyrene spp. and Nassarius spp. (see Szabó 2005).

The Kain Hitam rock art has not been dated, ${ }^{5}$ but the relative dates ascribed by Wilson (2003) for the curvilinear red tradition of the western Pacific fit seamlessly with the radiocarbon sequence for the site. Wilson (2003:277-278) goes on to make the important point that the curvilinear red tradition appears to be an outgrowth of the early Red1/Red 2 painting styles, with an infusion of new motifs generated, most likely, by the expanding contacts and networks of the Southeast Asian metal age. The Kain Hitam site, as a cohesive whole, reinforces this interpretation, with metal-age trade goods clearly being drawn into extant cultural practices. It seems clear to us that the rock art is not chronologically disjunct from the archaeological material. The same themes and motifs bind the two together, and when this point is combined with the highly ordered structuring of space within the site, it argues for a direct association.

\section{The symbolism of death: Kain Hitam and beyond}

Ballard et al. (2004) summarise the ethnohistorical and archaeological evidence for the interwoven nature of boat symbolism and death ritual in Southeast Asia (see also Manguin 1986). While there is no need to reiterate their discussion here, there are particular aspects which we would like to develop, related to (1) the intertwined dichotomy between the sacred/ profane or ritual/prosaic nature of boat and maritime themes in many Southeast Asian societies; and (2) the nature of the spatio-temporal patterning in boat/death symbolism, with the Kain Hitam evidence allowing us to tie together connections between mortuary expressions which have hitherto been overlooked. It is clear the Kain Hitam site is a very structured 'deathscape'. With a period of utilisation apparently in excess of 1000 years, the placement of items of material culture, including the death ships themselves, in relation to the rock art and the cave mouth remains constant. While this constancy clearly reflects replicative practice related to mortuary ritual and (at least outward) expressions of social relations, it also binds all the items of material culture together within such practice. This is significant in that many such items are traditionally interpreted as 'prosaic' items of material culture (see discussion of B. Harrisson's interpretation of Lobang Tulang above). In the context of Kain Hitam, spatial distributions and material associations make it plain that fresh-water shellfish remains, casting nets for fishing, and earthenware pottery are invested with meaning as a part of the deathscape. As suggested by Ballard et al. (2004:398), such blurring between the margins of the 'prosaic' and 'sacred' reflects the fundamental basis of the sacred in everyday patterns of life. At Kain Hitam, such everyday patterns clearly revolve around boats, and the movement of material goods, people and ideas.

The fact that boats and boat transport are structuring ideas within many and varied 
Southeast Asian societies is nothing new (e.g. Manguin 1986), and to leave the interpretation of the Kain Hitam site at such a point would be rather trite. Boat symbolism is clearly part of a wider conceptual structure that is expressed in a variety of different ways throughout insular Southeast Asia. The diversity in expression is, we feel, as important as the threads of connection. While the internal features of the Kain Hitam deposit are clearly highly structured, a wider gaze demonstrates that the location of Kain Hitam on the landscape itself is also structured. Located $91 \mathrm{~m}$ up a difficult cliff face, the cave of Kain Hitam is located over a point where the Sungai (River) Tangap ${ }^{6}$ disappears underground.

On noting this feature of geography, the Harrissons investigated other locales where tributaries in the vicinity of the Niah Caves disappeared underground, and found two more cave sites replete with death ships. ${ }^{7}$ Tom and Barbara Harrisson were quick to recognise the importance of such a location (T. Harrisson 1958, 1964), but did not fully explicate in print the importance of the river as a conduit between the worlds of the living and the dead.

While the location of the sites in relation to the river could be seen as fortuitous, there are a number of good reasons to think it is indeed important. Huntington and Metcalf (1979) elaborate a number of death rites from different ethnic groups in Borneo, and despite differences, strong themes are present. The Berawan of Long Jegan consider that souls travel upriver to the ancestral homeland, and in doing so, simultaneously move back in time, and from the everyday mundane world back past mythical ancestors to the realm of the sacred (Huntington and Metcalf 1979:72). Ngaju belief holds that the soul is transported on two different boats to the city of souls (Antoni 1982). Furthermore, the lance of the leader of souls takes the form of the mast of the boat, as well as a Garangin tree symbolising the tree of life at journey's end (Steinmann 1939:40; Schärer in Antoni 1982:150). The Maloh place the dead in dedicated structures set on high poles (kulambu), but transport the body to the kulambu in a boat-shaped coffin. Prohibitions were also placed on movement across the river during the period of mourning (King 1985:90, 191). Maloh cosmology holds that upstream regions of the river were associated with goodness, health, life and ancestral and aristocratic spirits, whilst downstream regions led directly to the land of the dead in the form of the underworld, populated by serpents and fish (King 1985:93). In the Philippines, the Sulod of Panay believe souls use rivers to travel between the lands of the living and the dead (Jocano 1970:187). One could continue listing examples, but as noted by van Gennep (1960 in Huntington and Metcalf 1979:12), 'water journeys and island-like afterworlds appear over and over again' as motifs in death rites and symbolism across very many cultures. The close association between boats, rivers, the afterworld and the ship-ofthe-dead motif seen in Borneo are replicated across Island Southeast Asia (Ballard et al. 2004).

Two mechanisms have traditionally been proposed for explaining these connections between cultural groups: (1) the influence of the Dongson culture of northern Vietnam with the expanding trade networks of the Southeast Asian metal age; and (2) demic diffusion of trading populations, resulting in a generally Sinicized cultural expression. We find both these explanations unsatisfactory, and believe a closer analysis of the nature and variability of mortuary expression across the region will illuminate why. Various ideas surrounding mortuary practices can be seen across the Island Southeast Asian region, often as far east as Remote Oceania. These include the ship of the dead, 'tree of life', animal associations including crocodiles, hornbills, sea serpents and turtles, and the curvilinear red art style (though not simply restricted to rock art) identified by Wilson (2003) for the western Pacific. While all of these elements have a wide geographical distribution, expression and recombination of elements differs. Here, we investigate mortuary expressions in Palawan, Philippines, as well as a new 'bronze ship' from Flores, Indonesia, to investigate both persistence and variability in the expression of major themes. 


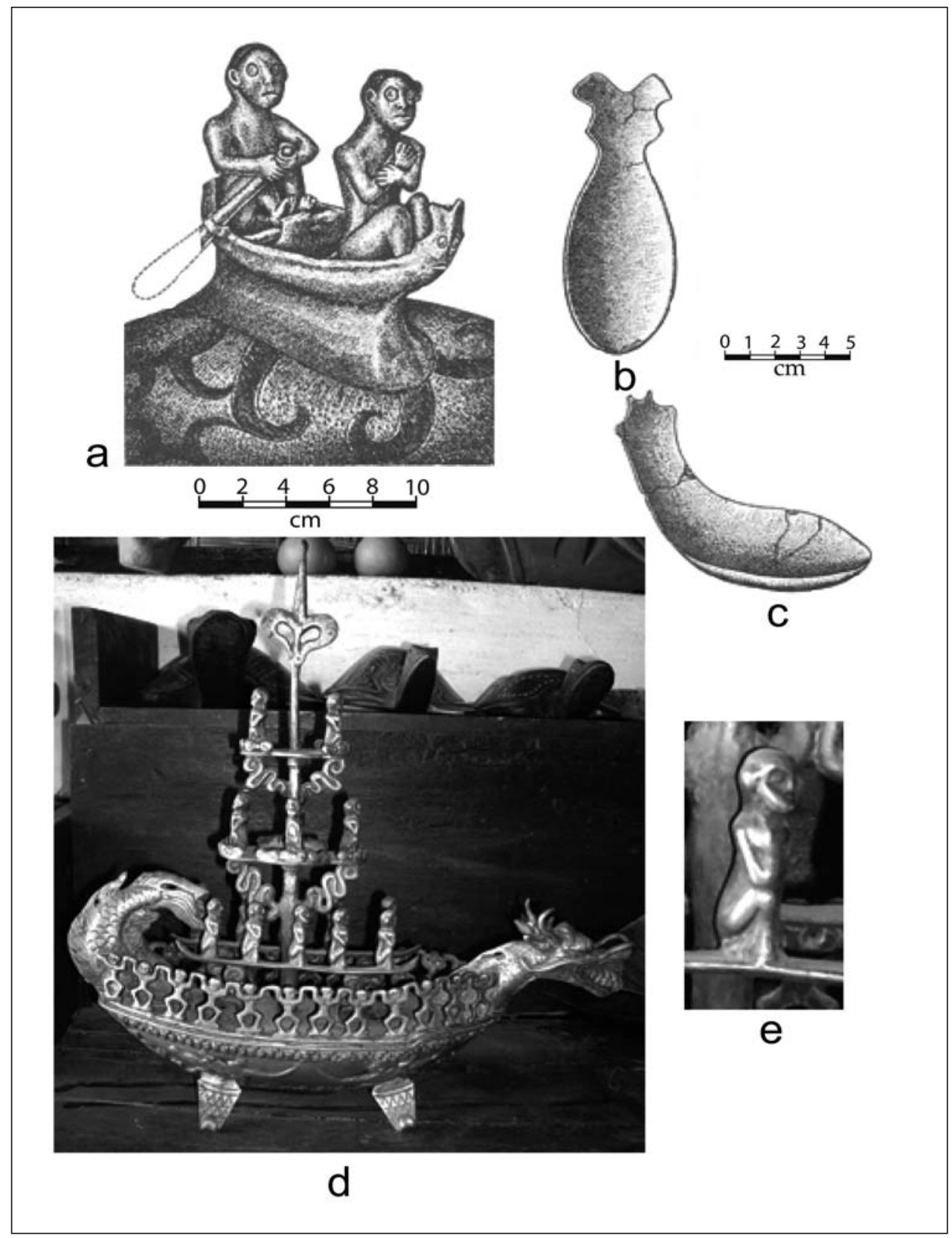

Figure 11. Ship-of-the-dead expressions from Palawan and Flores: (a) detail of the moulded lid of the Manunggul jar, Manunggul Chamber A, Palawan, Philippines (from Fox 1970); (b) and (c) Turbo marmoratus 'spoons' from the Tabon Caves complex (from Fox 1970); (d) cast bronze ship of the dead from Flores, Indonesia. Photographed by Szabó and Piper 2006 in Labuanbaju; (e) detail of seated figure from the Flores ship of the dead. Compare with (a). Figures $a, b$ and c reproduced with the permission of the National Museum of the Philippines.

The Manunggul Chamber A mortuary site within the Tabon Caves complex in Palawan, Philippines (Fox 1970), has yielded perhaps the most famous piece of Philippine earthenware: the Manunggul burial jar (Figure 11a). This large vessel is topped with a cover bearing a molded 'ship of the dead', where two figures sit in a vessel with a distinctively shaped figurative prow. Both figures gaze forward, with the rear figure steering and the front figure sitting with arms folded across his/her chest. The boat is assumed to have originally had a central mast/cosmic tree (Tenazas 1986:17). While the sculpture on the Manunggul jar has been repeatedly linked 
to ship-of-the-dead ideology since its discovery (Fox 1970:112-113), the association with redpainted curvilinear designs on the vessel itself is also worthy of note. Such designs are further replicated on various burial vessels from Ayub Cave, Mindanao (Dizon and Santiago 1996). The shape of the death ship is distinctive, and this precise design is replicated in artefacts produced in the large Turbo marmoratus shell, ${ }^{8}$ and generally referred to as 'spoons' (Figure $11 \mathrm{~b}$ and 11c). Such artefacts have been repeatedly found in metal-age burial contexts in Palawan, sometimes associated with jar burials (Szabó 2005:Chapter 6 for Batu Puti; Fox 1970:54, 118, 140 for Duyong Cave and Manunggul Chamber B), and sometimes with extended inhumations (Szabó 2005 for Leta Leta; T. Vitales pers comm. for Ille Cave).

While most of the spoons are in a clear metal-age association, a Turbo marmoratus shipof-the-dead artefact is associated with a firm Neolithic context in Leta Leta Cave, northern Palawan (Fox 1970; Szabó 2005), confirming the pre-metal presence of ship-of-the-dead beliefs in this region. Such 'spoons' have also been excavated from other Philippine locales (Bautista 1996), as well as from the Ryukyu Islands, southern Japan (e.g. Takemoto and Asato 1993), and from southern Taiwan ( $\mathrm{Li}$ 1983), but have not been recovered from Borneo or Indonesia.

An arresting example of death-ship imagery comes from Flores Island in eastern Indonesia in the form of a cast bronze sculpture recorded by Szabó and Piper in Labuanbaju, Flores, in 2006 (Figure 11d and Figure 11e) (see Adams 1977 for a different example). Many elements of death imagery combine in this piece, including the crocodiles around the hull of the boat (see Tenazas 1986 for more examples of crocodile imagery and death in the Philippines and Borneo), the central tree-of-life mast, and the sea-serpent form of the bow and stern. The similarity between the seated figures (Figure 11e) and those represented on the Manunggul jar can hardly be missed, and the frieze of stylised figures around the edge of the deck mirror those represented in the Kain Hitam rock art.

While the Kain Hitam deathscape, mortuary sites in Palawan, and the Flores bronze ship are strongly connected in terms of imagery, the differences in expression and context must not be forgotten. There are no clear, recurrent linkages between the types of burial (i.e. jar burial, death ship, primary extended inhumation) and associated imagery. Thus, while ship-of-thedead imagery is apparently confined to death-ship contexts in Sarawak, it is associated with both jar and primary extended burials in Palawan. Media and modes of expression are likewise different, with a complete absence of prehistoric rock art in Palawan, and differing associated artefacts, with bone ornaments near absent in Palawan and expressions in shell being rather understated in Sarawak.

Tantalising lines of evidence further suggest in Sarawak and Palawan that ship-of-the-dead beliefs pre-date the metal age. Variability in mortuary expression has implicitly or explicitly been assumed to represent chronological patterning (e.g. Bellwood 1997:296), but the evidence from Niah, coupled with that from Palawan, demonstrate that these various articulations are, at least to some degree, synchronous (see also Tenazas 1986:15). Thus, while Kain Hitam is characterised by boat burials, Lobang Tulang is a jar-burial site, and Gan Kira has extended burials including Tom Harrisson's 'murder' type.'

Associated artefacts of both local and foreign manufacture, however, overlap between all three sites, stalling any interpretation that would seek to attribute the differences to distinct cultural groups. There are those who have attributed later prehistoric burial practices at Niah and elsewhere in Sarawak to Chinese immigrants (e.g. Chêng 1969), and there are some obvious Chinese parallels in beliefs surrounding death, including watery journeys, crocodiles, sea serpents and trees of life (see Antoni 1982 for a discussion of Wang Ch'ung's Lun-heng 27-97 AD). According to Rawson's (1998) analysis of changing mortuary expressions in China, many of these 
distinctive beliefs in animal spirits and 'imaginary' beings are found in the southern Chinese record contemporaneous with very different Shang (c. 1200-1050 BC) and Western Zhou (c. 1050-771 BC) expressions in the north (Rawson 1998:122). She also points to a growing incorporation of these southern belief systems detectable from the Eastern Zhou (771-221 BC) into the Han Dynasty (BC 206-220 AD) as China was unified (Rawson 1998:112-113, 122).

The links between the Southeast Asian evidence and that of southern China - perhaps associated with the 'Hundred Yueh' - hint that such belief systems may not originate in 'China', but were already extant among local indigenous peoples with connections to Southeast Asia. The continuity witnessed in the Southeast Asian archaeological record across the Neolithic/ metal-age boundary further serves to confound an attempt at unsubtle Sinicization.

Rather than simply attributing any (perceived) change to immigrant populations, the more popular mechanism invoked for explaining the wide spatial distribution of cultural expressions of the Southeast Asian metal age is the influence of the Dongson culture of northern Vietnam (e.g. Harrisson 1958; Spriggs in Wilson 2003:277; Ballard et al. 2004:393). Tangibly, this influence is seen in the wide distribution of bronze kettle drums of Dongson manufacture, ${ }^{10}$ but it has been the boat motifs incised on the drums which have perhaps been credited with widespread influence. Such motifs have encouraged an interpretation in which the Dongson culture is seen as the progenitor of ideas such as the 'ship-of-the-dead cult', with an influence (e.g. economic, stylistic) that spread to encompass insular Southeast Asia and as far as Near Oceania (e.g. Goloubew 1929; van Heekeren 1958:96; Badner 1974). While the clear presence of 'shipof-the-dead' philosophies in Neolithic Island Southeast Asia could alone act to undermine the directionality of such connections, we feel that such interpretations mask, rather than elucidate, the interactions developed and sustained by maritime contact.

Thomas (1991:27) points out that socio-economic evolutionary thinking turns on and recapitulates the divisions between 'modern' and 'traditional' societies. The assumed impact of metal and prestige trade goods from the Asian mainland into Island Southeast Asia can be seen in this light. Thomas (1991:27) suggests it should not be the [pre-]historian's aim to shift such divisions back in time, 'but rather to displace such exercises through an analysis of process and grounded regional distinctions which actually relate to peoples rather than rhetorical types'. Recognising this, any analysis of 'influence' and 'trade' must consider how new goods and ideas were integrated into local economies and psyches. It is this appropriation and reinterpretation of foreign goods and ideas that patterns the archaeological record, rather than any simple presence of strangers or trading vessels. In the words of Thomas (1991:88):

Indigenous interests in trade are not presumed to be straightforward or predictable but must instead be contextualized in prevailing ideas of what foreign visitors and their goods represented. This cultural context is not easy to apprehend, especially since interpretation must be based mainly upon what can be discerned of indigenous reactions at the time ... But the analytical problems must not prevent us from attempting to give an account of the local way of recognizing new strangers: these perceptions conditioned what was at stake in contact and exchange.

With reference to Kain Hitam, the spatial/structural replication of burial practices over a 1000-year period, with the simple insertion of overseas trade goods into this structure when they entered local economies, testifies to the local continuity through this economic 'transition'. It is clear that boats, water, maritime contacts and connections between worlds over water were already configuring features of indigenous consciousness, as represented by death ships, casting nets, shark vertebrae beads, the rock art and the (votive?) deposits of fresh-water shell. Such expressions can also be clearly seen in Palawan and elsewhere throughout the Island Southeast 
Asian region, but they manifest in different ways. These entangled connections projected through local response serve to remind us that trade goods and (seemingly) extra-local ideas should always be 'interpreted in the context of the place into which they are introduced, and not taken as essences that have merely been moved physically from places of origin' (Thomas 1991:186).

\section{Endnotes}

1. The name Kain Hitam literally translates as 'Black Cloth' in Bahasa Melayu.

2. It is worthy of note that published photographs of the Kain Hitam death ships (e.g. Harrisson 1958, 1960) were 'staged' by Harrisson, and do not represent the original positions of the boats.

3. Solheim (1983) states that the Kain Hitam ceramics more likely date to the 14th-15th century $\mathrm{AD}$, however it appears that this upward revision was not based on an analysis of the material. Given the disjuncture between other features of the site and a Ming-period age for the trade wares, we continue with Tom Harrisson's chronology, although further analysis of the Kain Hitam trade wares would be valuable.

4. Francis (2002:77) comments on the Kain Hitam glass beads, relying on the commentary by Solheim (1983), and thus duplicates the erroneous conclusions that there were no Chinese ceramics in Sarawak before the 10th century AD, and no coil beads at other Sarawak sites until the 12th century AD.

5. Dating of the rock art from Kain Hitam has been attempted, but was unsuccessful due to the low organic levels.

6. Erroneously referred to by Tom Harrisson as the 'Subis River' (T. Harrisson 1958:202).

7. One of these sites is the 'Samti' site, while the other is unnamed. Both are apparently located in the Great Cave within the Niah system (see Harrisson 1958).

8. Such artefacts were originally thought by Fox (1970) to have been produced in the Chambered Nautilus (Nautilus pompilius), however further study (Bautista 1996; Szabó 2005) has confirmed Turbo marmoratus as the raw material.

9. Tom Harrisson's 'murder' burials are primary extended burials demonstrating violent deaths. One example from Gan Kira has the shaft of a spear still protruding from the body.

10. Although, notably, no bronze drums have been recorded for the Philippine archipelago, and few from Borneo.

\section{Acknowledgements}

The analysis of the Kain Hitam material was made possible through a British Academy Small Research Grant to the authors. The British Academy also funded the new radiocarbon determinations for Kain Hitam. Katherine Szabó was assisted in the shell analysis by HsiuYing 'Shawna' Yang and Christopher Wong. We thank the Sarawak Museum for their ongoing support, and in particular Haji Sanib bin Said, Ipoi Datan and Noel Laman of the Niah Museum. At Niah Caves National Park, we wish to thank Abang Mutalib, Madame Rose and Lyn; and in Kuching, Helen bin Kurui. We thank Corazon Alvina and Eusebio Dizon of the National Museum of the Philippines for permission to reproduce the drawing of the Manunggul jar from Fox (1970). For discussion of particular points and assistance with references, thank you to Meredith Wilson, Chris Ballard, Douglas Farrer, Christopher Stimpson, Lindsay Lloyd-Smith, the Earl of Cranbrook and Judith Cameron. 
We also thank the Corning Glass Museum for locating and sending the results of analysis of glass samples originally sent by Tom Harrisson. For further information on mortuary deposits in the Philippines, we thank Jack Medrana and Grace Barretto-Tesoro, and for assistance with references, Janine Ochoa and Isa Campos.

\section{References}

Adams, M.J. 1977. A "Forgotten" Bronze Ship and a Recently Discovered Bronze Weaver from Eastern Indonesia: A Problem Paper. Asian Perspectives 20:87-109.

Antoni, K. 1982. Death and Transformation: The Presentation of Death in East and Southeast Asia. Asian Folklore Studies 41:147-162.

Badner, M. 1974. Some evidences of Dong-Son-derived influence in the art of the Admiralty Islands In N. Barnard (ed.), Early Chinese Art and its Possible Influence in the Pacific Basin, pp. 597-629. New York: Columbia University.

Ballard, C., R. Bradley, L. Nordenborg M. and M. Wilson 2004. The ship as symbol in the prehistory of Scandinavia and Southeast Asia. World Archaeology 35:385-403.

Barretto, M.G.L.D 2002. Evaluating status in Philippine Prehistory through grave goods. Unpublished MA, University of the Philippines, Diliman.

Basilia, P., A. Bautista and K. Szabó 2006. Post-Neolithic Shell Beads from Ille Cave, El Nido, Palawan: A Case of Specialisation?, Paper presented at the 18th Indo-Pacific Prehistory Association Congress, Manila 2006.

Bautista, A. 1996. Shell Spoon from Chamber B of Manunggul Cave, Palawan and Mataas Site Albay: Nautilus or Turbinate Shell? National Museum Papers 6:59-63. (National Museum of the Philippines).

Bellwood, P. 1997. Prehistory of the Indo-Malaysian Archipelago, Revised edition. Honolulu: University of Hawaii Press.

Bellwood, P., J. Cameron, N. Van Viet and B. Van Liem 2006. Ancient Boats, Boat Timbers, and Locked Mortise-and-Tenon Joints from Bronze/Iron-Age Northern Vietnam. International Journal of Nautical Archaeology 36(1):2-20.

Brill, R.H. 1999. Chemical Analyses of Early Glasses, Volume 1, Catalogue of Samples. New York: The Corning Museum of Glass.

Chêng, T. 1969. Archaeology in Sarawak. Cambridge: W. Heffer and Sons and the University of Toronto Press.

Dizon, E.Z. and R. Santiago 1996. Faces From Maitum: The Archaeological Excavation of Ayub Cave. Manila: National Museum of the Philippines.

Fox, R.B. 1970. The Tabon Caves. Manila: National Museum of the Philippines.

Francis, P. Jr. 2002. Asia's Maritime Bead Trade: 300 B.C. to the Present. Honolulu: University of Hawaii Press.

Glover, I. 1972. Excavations in Timor. Unpublished PhD thesis. Department of Prehistory, Research School of Pacific Studies, Australian National University.

Goloubew, V. 1929. L'age du bronze au Tonkin. Bulletin de l'École Française d'Extrême-Orient, 29:1-46.

Gompertz, G. St. G.M. 1958. Chinese Celadon Wares. London: Faber and Faber.

Harrisson, B. 1958. Niah's Lobang Tulang: ("Cave of Bones"). Sarawak Museum Journal 8:596-619.

Harrisson, B. 1959-60. Cave of Bones - New Finds, 1959. Sarawak Museum Journal 9:164-178.

Harrisson, B. 1967. A classification of Stone Age burials from Niah Great Cave, Sarawak. Sarawak Museum Journal 15:126-200.

Harrisson, T. 1958. The Great Cave Sarawak: A Ship-Of-The-Dead Cult and Related Rock Paintings, The Archaeological News Letter. 6:199-204. 
Harrisson, T. 1960. Stone Age Ships of Death: World's oldest boat coffins found in Sarawak caverns reveal ancient culture. Life, January 11 1960, pp. 49-51.

Harrisson, T. 1964. 100,000 Years of Stone Age Culture in Borneo. Journal of the Royal Society of Arts (1964):174-191.

Harrisson, T. and B. Harrisson 1971. The Prehistory of Sabah. Sabah Society Journal, Monograph 4.

Harrisson, T. and Lord Medway 1962. A first classification of prehistoric bone and tooth artifacts (based on material from Niah Great Cave). Sarawak Museum Journal 11:335-362.

Hudson, B. 2003. Dental Wealth. Archaeology News, July/August 2003, p. 10.

Huntington, R. and P. Metcalf 1979. Celebrations of Death: The Anthropology of Mortuary Ritual. Cambridge: Cambridge University Press.

Jocano, F.L. 1970. Death, Bone Washing, and Jar Burial among the Sulod of Central Panay, Philippines. In R. Fox (ed), The Tabon Caves, pp. 181-188. Manila: National Museum of the Philippines.

Lape, P., S. O’Connor and N. Burningham 2007. Rock Art: A Potential Source of Information about Past Maritime Technology in South-East Asia-Pacific Region. International Journal of Nautical Archaeology 36:238-253.

Li, K. 1983. Report of Archaeological Investigations in the O-luan-pi Park at Southern Tip of Taiwan. Taipei: Kenting Scenic Area Administration, Ministry of Communication; Department of Anthropology, National Taiwan University; Council for Cultural Planning and Development, Executive Yuan.

Manguin, P.Y. 1986. Shipshape societies: boat symbolism and political systems in insular Southeast Asia. In D.G. Marr and A.C. Milner (eds), Southeast Asia in the 9th to 14th Centuries, pp. 187-213. Canberra: Institute of Southeast Asian Studies and Research School of Pacific Studies, Australian National University.

Moore, E. n.d. Bukit Saripah Cave. Kuching: Unpublished typescript, Sarawak Museum.

Munan, H. 2005. Beads of Borneo. Singapore: Editions Didier Millet.

Pyatt, F.B., B. Wilson and G.W. Barker 2005. The chemistry of tree resins and ancient rock paintings in the Niah Caves, Sarawak (Borneo): Some evidence of rain forest management by early human populations. Journal of Archaeological Science 32:897-901.

Rawson, J. 1998. Chinese Burial Patterns: Sources of Information on Thought and Belief. In C. Renfrew and C. Scarre (eds), Cognition and Material Culture: the Archaeology of Symbolic Storage, pp. 107-133. Cambridge: McDonald Institute for Archaeological Research.

Solheim, W.G. II. 1983. Archaeological Research in Sarawak, Past and Present. Sarawak Museum Journal 32:35-58.

Spriggs, M., P. Veth, S. O’Connor, H. Mohammad, A. Jatmiko, W. Nayati, A. Diniasti and D. Witjaksono 2005. Three seasons of archaeological survey in the Aru Islands, 1995 - 1997. In

S. O'Connor, M. Spriggs and P. Veth (eds), The Archaeology of the Aru Islands, Eastern Indonesia, pp. 63-83. Terra Australis 23, Canberra: Pandanus Press.

Szabó, K. 2005. Technique and Practice: Shell-working in the western Pacific and Island Southeast Asia. Unpublished PhD thesis, Australian National University.

Szabó, K. and H-Y Yang In preparation. Shell net-sinkers from casting nets: an exercise in identification.

Szabó, K. In preparation. The Molluscan Remains from the Niah Caves. In G. Barker, D. Gilbertson and T. Reynolds (eds), The Archaeology of the Niah Caves, Sarawak: Excavations 1954- 2004. vol. 2. Cambridge: McDonald Institute for Archaeological Research.

Takemoto, M. and S. Asato 1993. Nihon no Kodai Iseki: 47 Okinawa: Hoikusha.

Tenazas, R. 1986. The Boat-Coffin Burial Complex in the Philippines and its Relation to Practices in Southeast Asia. SPAFA Digest 4:11-18.

Thomas, N. 1991. Entangled Objects: Exchange, Material Culture, and Colonialism in the Pacific. London: Harvard University Press, Cambridge MA. 
Van Heekeren, H.R. 1958 The Bronze-Iron Age of Indonesia. Gravenhage: Martinus Nijhoff.

Wilson, M. 2003 Rock-art transformations in the western Pacific. In C. Sand (ed), Pacific Archaeology: assessments and prospects, pp. 265-284. Noumea: Service des Musées et du Patrimoine.

Zuraina M. 1982. The West Mouth, Niah in the prehistory of Southeast Asia. Sarawak Museum Journal 31(3):1-200. 